\title{
A Rural Perspective of Telephone Counselling and Referral
}

\author{
Robert J. Watson \\ B.A. Hons. (PhD. Candidate) (Ballarat) \\ And \\ John McDonald \\ Assoc Professor (Ballarat)
}

Correspondence: Robert Watson,

School of Behavioural \& Social Sciences \& Humanities,

University of Ballarat, PO Box 663, University Drive, Mt Helen,

Ballarat, Victoria, 3353, Australia.

Phone: (03) 53279197

Email: rwatson@students.ballarat.edu.au

Fax: 0353279840 


\begin{abstract}
A telephone survey was used to examine rural residents' $(n=102)$ perceptions and knowledge of a well-established national telephone counselling and referral service: Lifeline. Residents in rural Australia experience generally poorer access and availability to health related services than metropolitan counterparts. They may also have problems with confidentiality and stigmatisation with using what services are available in their area. Although this was a non-comparative study, it was reasoned that these barriers to help seeking in rural areas would mean its population would know and value a service such as Lifeline, which provides equitable and anonymous support and referrals to all Australians. The results showed that the service was known, valued, and supported strongly by the respondents. The findings supported the belief that telephone counselling and referral has an important and unique place in rural health support and referral.
\end{abstract}


Areas outside major metropolitan centres in Australia are characterised by considerable geographical and social diversity (Fraser et al., 2002; Hugo, 2001; Wainer \& Chesters, 2000; Welch, 2000). It is well acknowledged however, that rural Australians experience generally poorer access and availability to health related services than metropolitan counterparts (see Australian Institute of Health and Welfare [AIHW], 2002; Cheers, 1998; Meadows, Singh, Burgess, \& Bobevski, 2002). In the Health Belief Model (Rosenstock, 1990) barriers such as inaccessibility to health services can be seen as an impediment to help seeking behaviours. Telephone counselling and referral services provide equitable health services, with few barriers to prevent rural and remote Australians from receiving care. This paper explores the role of telephone counselling and referral services in rural Australia, and presents a rural perspective of the Lifeline service via a random telephone survey in a large and diverse rural region of Victoria.

Telephone counselling was first used widely by suicide prevention and crisis intervention services in the 1960s, as a means of providing immediate and inexpensive access to crisis intervention for those in distress (Lester, 2002). Bobevski and Holgate (1997) suggested that telephone counselling services tend to be of three types. The first are the large community agencies that provide 24-hour telephone counselling to the general community, such as the Samaritans in Great Britain and Lifeline in Australia. The second are those that provide very specific telephone counselling services for those with particular needs and groups (e.g. Gayline, Kids Help Line). The third type is health and welfare agencies offering telephone counselling within normal business hours. The second and third types of telephone service may be referral points available from the more generalist 24-hour agencies such as Lifeline. 
Lifeline’s telephone counselling and referral service grew from humble beginnings in Sydney, Australia and it is now a leading national and international organization in its field. Lifeline has over 40 centres in Australia, based in every state and territory. Lifeline as a generalist telephone counselling and referral service, takes calls on a wide variety of issues from the general public 24 hours a day, seven days per week. It provides an anonymous and confidential service, and most calls to it (up to $80 \%$ ) are about problems the caller is facing (Lifeline Australia, 2002). Lifeline’s service is frequently used. In a typical 24-hour period more than 1000 calls will be answered nationally (Lifeline Australia, 2002). The service can be reached from anywhere in Australia for the cost of a local call on the one number 131114.

It seems well established that telephone counselling services can help to avert some personal tragedies such as suicide (Cheers, 1998), but these calls make up only a small percentage of the overall calls to the service (Lifeline Australia, 2003). In addition telephone counselling and referral services may have a role in more primary intervention. For example, they provide social support to the lonely and socially isolated who are at increased risk of disease such as coronary heart disease (see Bunker et al., 2003; Hemmingway \& Marmot, 1999). This may be an important unrecognised function of the service (see Lazer \& Erera, 1998; Watson \& McDonald, 2003).

Telephone counselling services have been identified as having unique features, many of which make their services particularly suited to the needs of nonmetropolitan and isolated Australians. A number of authors (Community Services Victoria \& Health Department of Victoria, 1988; Hambly, 1984; Rosenfield, 1997; Coman et al., 2001; Lester, 2002) have suggested that immediacy and accessibility of phone counselling are important advantages to telephone counselling use. For 
housebound callers, people in rural communities, and isolated individuals, a telephone counselling service may be essential (Coman et al., 2001).

Telephone counselling can reduce feelings of isolation and despair while people are still based in or confined to their homes (Community Services Victoria \& Health Department of Victoria, 1988). The low cost of the call, the price of a local call in the case of Lifeline, means that access is not prohibited by financial constraints or geographic distance. Immediacy of access and general availability of the service wherever or whenever it is needed, are other advantages of telephone counselling. The control given to the caller by being able to easily end the call, and the anonymity and confidentiality of the meeting are further factors contributing to telephone counselling's growth and popularity (Coman et al., 2001; Hetzel, Wilkins, Carrig, Thomas, \& Senior, 1993; Hambly, 1984; Lester, 2002; Rosenfield, 1997).

These enabling features of telephone counselling seem to offer distinct advantages to rural clients who may have access and confidentiality issues with local health service use (Cheers, 1998). Clients who are well known in a rural community may be reluctant to seek face-to-face counselling from services located within the community. A traditional stereotype of rural masculinity is associated with stoicism and a stigma attached to seeking help with problems (Wainer \& Chester, 2000). Stigmatisation and confidentiality issues may be responsible for reluctance to accept formal services in rural areas (Letvak, 2002), even if they are available. Telephone counselling means people can gain access to a counselling and referral service whilst they maintain their anonymity and dignity (Coman et al., 2001). The information and referral role of telephone counselling and referral services is a critical one and is rightly perceived by most service providers as extremely important (Community Services Victoria \& Health Department of Victoria, 1988). 
It would seem that there are enabling features of telephone counselling and referral that would make such services as Lifeline an important and valued part of a health and welfare support system in rural areas. To investigate this, a survey was prepared to examine rural residents' perceptions and knowledge of the telephone counselling and referral service, with particular regard to Lifeline. A 26 question interview instrument was specifically produced for the study. The interview instrument was used to assess: participants' awareness of the Lifeline telephone counselling and referral service; knowledge of its access; preparedness to use the service; possible circumstance of use; perceived advantages and disadvantages of using a telephone counselling service; and demographic information about the participant.

\section{Method}

\section{Participants}

The sample consisted of 102 (63 female and 39 male) residents of rural Victoria who agreed to participate in a five-minute telephone interview. The respondents' ages were from late teens to over 76 years, and they reported a variety of occupations. The sample frame numbered 322 individual telephone numbers. One hundred and fortythree people declined to take part. Forty-seven numbers were on answering machines when contacted, and a further 28 calls were either unanswered, disconnected, or to businesses. Two participants withdrew during the interview and their data were not included in the sample. The University of Ballarat Human Research Ethics Committee approved the project and the method before any data were gathered. 


\section{Materials}

The 2002-2003 Ararat, Bacchus Marsh, Ballarat, Horsham, Nhill and Stawell White Pages ${ }^{\circledR}$ was used to draw up the sample frame. Random phone numbers were generated on a Casio fx-825 calculator. A researcher conducted the interview using the telephone. The questionnaire used in this study to assess participant's knowledge of the Lifeline service was created specifically for the task. The questionnaire had 26 items, which were created in conjunction with Lifeline Ballarat. A short form of the questions used by the instrument is shown in Table 1 and the results section.

\section{Procedure}

Phone numbers were collected from the white pages of the phone book to produce a sample frame. An initial page was chosen by the production of a random number on a hand held calculator. This page was then designated the starting page. Another random number then gave an entry on that page, which was then listed in the sample frame. If this number were a business entry, the next available private address down that column of the page would be added to the frame. Using this process for each page in turn, all white pages of the phone book (215 pages) produced a least one entry to the total sample frame.

Calls were conducted at various times of the day and week, however, most were conducted on a Saturday between the hours of 9-30 am and 12 noon, and 1pm and 5pm. On reaching a person, the interviewer read a protocol for recruiting participants, in which the person was asked to participate in the interview. If the participant decided to participate he/she was then asked the questions from the interview instrument, and then thanked for their participation. If the participant declined, they were thanked and were apologised to for the inconvenience. 
If a number was not answered on the first occasion it was called again at a later time. All numbers were tried on at least two occasions. Both male and female interviewers conducted the interviews, with interviews taking approximately five minutes to administer.

\section{Results}

Table 1 presents a short form of each question, the number of responses and the proportion of the total response. A number of questions were asked only of the 91 respondents who had heard of the service, as suggested by the response to the first question that asked if they had heard of the service. Five questions had open ended responses and are also summarised in this section.

Participants were told that "The Ballarat office of Lifeline received around 10,000 calls last year”. They were then asked, “What would you think is the central issue/ problem involved with many of these calls?” The responses to this question varied considerably and some of the more frequent responses given were as follows: calls about depression ( $n=9)$; financial problems $(n=7)$; depression and loneliness ( $n=6)$; loneliness $(n=4)$; abuse $(n=3)$ and domestic violence $(n=3)$.

Participants were asked, "Under what circumstances would you think you or someone you know might consider calling Lifeline?” The responses to this question showed that depression ( $n=10)$, 'last resort' $(n=10)$, financial $(n=7)$, family $(n=6)$ and crisis $(n=6)$ issues or problems were the most likely to lead the participant or someone they know to call Lifeline. These responses were then assigned to one of 11 Lifeline Client Service Management Information System (CSMIS, Cameron, 2001) issue categories. Table 1 presents the percentages of participants responding with answers that were assigned to each of these categories by this researcher. As there was no clear 
category for crisis $(n=6)$, suicide $(n=5)$, or desperate $(n=5)$ these responses were grouped together as 'Crisis' in Table 1. The participants who could not provide an answer to this question were grouped in the 'never' category. However, only three participants gave 'never’ as the response (2 male and 1 female).

Participants were asked for any comments on the Lifeline service. Forty-one comments were collected with answers such as: 'absolute necessity'; 'need to have it'; ‘very important’; ‘marvellous’; ‘more funding’; ‘vital community service’; ‘important’; ‘reasonably good job’; ‘have not heard much about it’; ‘hope it continues’; ‘wonderful’; ‘advertise more widely’; ‘bloody good job’; ‘fantastic service' and 'very much appreciated'. Only two negative responses were found: “counsellors have their own problems” $(n=1)$ and trouble with access to service $(n=1)$. Also, the need for more advertising of the service was noted $(n=3)$.

Participants were asked, “ What advantages do you think a telephone counselling service might have over other forms of counselling?” The responses to this question showed the suggested advantages of using a telephone service to be spread across 13 themes. The most common response theme was 'anonymity' with 40 responses. The other themes were: twenty-four hour help $(n=10)$; immediacy $(n=12)$; confidential ( $\mathrm{n}=8)$; easy access $(n=5)$; private $(n=4)$; no waiting $(n=3)$; caring $(n=2)$; useful ( $n=2)$; not face to face $(n=2)$; less confrontational $(n=2)$; useful advice $(n=1)$; cost $(n=1)$; no advantage $(n=1)$ and 9 were unsure.

The participants were asked, "What would you say are the greatest disadvantages of using telephone counselling?” The responses to this question showed the sample provided a varied response to disadvantages of telephone counselling. The major theme was the incapacity for face-to-face counselling $(n=18)$ and personal contact $(\mathrm{n}=11)$. 
Insert Table 1

About here

\section{Discussion}

The results show that a large majority of respondents were found to be aware of the Lifeline telephone counselling and referral service. The respondents also attached considerable community value to the service, a number having personal experiences of its use. Respondents showed knowledge of the advantages and disadvantages of telephone counselling. They also showed strong support for the service's continuation. These findings would seem to support the idea that Lifeline is seen as an important and valued part of rural health and welfare support system by rural people.

Geographical proximity to a service alone will not guarantee its use when needed, and other factors of accessibility may determine one’s decision to seek health services (Humphreys, Mathews-Cowey \& Weinand, 1997; Walsh, 1995). For example, an awareness of a service's existence is crucial to its use. The results of this study showed that the Lifeline telephone counselling service’s name was recognised by $89 \%$ of the respondents. Such a finding would indicate that the rural residents contacted are generally aware of the availability of the service. Seventy-five percent of respondents knew the service operated 24 hours per day, seven days a week. This finding suggests a good knowledge of its temporal availability. Subjective ratings by the 91 respondents, who knew of the Lifeline name, suggested their self perceived knowledge about the service was not as strong as these two replies may suggest. Fiftyone participants responding they had 'very little’ knowledge and a further three saying they had no knowledge, with only seven responding they were well informed. 
Humphreys et al. (1997) found rural people use and choose medical services not merely on their need for them, but also their perceptions of them and the value they place in them. The individual's perceptions are also fundamental to behaviour from the perspective of the Health Beliefs Model (Rosenstock, 1990). From the survey results it would seem that the respondents placed a high value on the Lifeline service. Both males and females gave equally high appraisals for its value to the community, however females have been noted to use the service with greater regularity than men (Lifeline, 2003). No respondent said the value of the service to the community was zero or 'poor', the lowest possible response values. Of the 14 participants who had 'no idea' about the service's value, nine were people who had not heard of the service at question one, and three admitted to knowing little more about the service than its name.

Many respondents showed an understanding of the advantages and disadvantages of telephone counselling, as well as knowledge about its general operations. Advantages such as anonymity and immediacy were well acknowledged by the respondents. If ' 24 hour access', 'no waiting', and 'easy access' themes responses were combined with immediacy, then this theme would have accounted for 30 responses. Adding anonymity to this immediacy total would produce 70 responses, over $68 \%$ of the sample, who reported these two attributes were the greatest advantages of telephone counselling. This finding supports the contention that anonymity and ease of access would be highly valued by rural people. Only one respondent thought that telephone counselling had no advantage.

It is worth noting that anonymity could be seem as both an advantage and disadvantage of telephone counselling, even by the same person. This finding, supported by verbal clarifications from some of the respondents, suggested that for 
some situations the respondent could seek telephone counselling for the anonymity it provides, but have preference for seeking face-to-face counselling for other situations. This finding supports the argument that telephone counselling is complementary to, but distinctive from, face-to-face counselling (Community Services Victoria \& Health Department Victoria, 1988; Hornblow, 1986).

The overwhelmingly positive nature of the comments about the service is a further indicator that the service was generally valued and perceived of in a positive way. When asked for circumstances that might provoke a call to Lifeline, only two males and one female said they could think of no reason for them to ever call the service. This would seem to suggest the vast majority of the sample could conceive of a situation where they would use the service. With the knowledge of the service, the strong value of the service to the community and positive perceptions shown in this study, it might be expected that some of this sample may have indeed been prepared to use this service. Although not on the questionnaire, 28 percent of respondents did respond 'yes' when asked if they or someone they may know had ever used the service.

There were a number of limitations to the result that are common and, in many cases, unavoidable in even the most well designed telephone survey (see Steel, Vella, \& Harrington, 1996). However, by identifying Lifeline and the nature of the interview before asking for the respondents' consent to continue, a self-selection bias may have been introduced. This may have meant that participants with knowledge of the service may have therefore been more prepared to take part than participants who did not know the service. Participants refusing to continue, at this point, and stating they knew nothing about the topic made this apparent to the interviewers on a number of occasions. Even when they were assured this did not matter there was still reluctance 
to take part. Therefore, this possible self-selection bias, paired with a response rate little better than a third of the total sample frame, could affect the result considerably. Thus, generalisation of these results is not recommended. However, it would be interesting to see if these results would be repeated in metropolitan areas, even if the same procedure and possible bias were introduced. Further, this was a noncomparative study, so we do not know whether metropolitan people know more or less about the service or even if it is used disproportionately in rural areas.

In the past rural general practitioners have assumed the role of healer, carer, counsellor and friend (Humphreys et al., 1997). Changes to general practice have occurred along with a decline in bulk billing and general practice availability in rural Australia. This may mean that telephone counselling and referral services are needed to take on the carer, counsellor and friend role once provided by the local GP or others in the community. The generally increasing rates of use and the growing numbers of services across time would suggest they are meeting a growing need worldwide. However, the relative use and patterns of use of telephone counselling in rural and remote areas as opposed to metropolitan areas of Australia is not clear at this time.

To a degree, these findings confirm the value of the Health Belief Model (Rosenstock, 1990) in explaining the likelihood of a person's decision to utilise telephone counselling. This Model holds that individuals evaluate their perceived susceptibility to, and severity of, poor health, and assess the costs and benefits of accessing treatment. This is evident in the results of this study pertaining to the circumstances (such as crises) that would lead someone to call Lifeline, the value of the service, and their preference to use it above other services. This research also suggests that the Health Belief Model should be extended beyond the psychosocial. In a rural setting, community factors, such as the level of a person's social support and 
concerns about the confidentiality of services, come to the fore. The ways in which ‘place’ structures social relations and influences health behaviour may also open up useful theoretical lines (Kearns \& Moon, 2002).

Knowledge of Lifeline's accessibility, perceptions of its value to the community and an understanding of its service were clearly recognised by respondents in this survey. If these factors are a guide to the possible usage of the service, as suggested by the Health Beliefs Model and the findings of Humphreys et al. (1997), then Lifeline’s telephone counselling and referral service should be well utilised by rural Australians. The findings of this study support the belief that telephone counselling and referral services have an important and unique role in rural and remote health and wellbeing. 


\section{Acknowledgements}

The authors wish to thank Ballarat UnitingCare Out-Reach - Lifeline Ballarat for their assistance with this survey. They would also like to thank the Australian Research Council and industry partners Lifeline Australia Inc and Ballarat UnitingCare Out-Reach - Lifeline Ballarat for their continuing support. 


\section{References}

Australian Institute of Health and Welfare (AIHW). (2002). Australia's health 2002.

Canberra: Australian Institute of Health and Welfare.

Bates, B. (1978). Lifeline (Melbourne): A case study in the use and training of volunteer telephone counsellors. Bundoora: Preston Institute of Technology Press.

Bobevski, I., \& Holgate, A. M. (1997). Characteristics of effective telephone counselling skills [Electronic version]. British Journal of Guidance \& Counselling, 25, 239-249.

Brown, W. J., Young, A. F., \& Byles, J. E. (1999). Tyranny of distance? The health of midage women living in five geographical areas of Australia. The Australian Journal of Rural Health, 7, 148-154.

Bunker, S. J., Colquhoun, D. M., Esler, M. D., Hickie, I. B., Hunt, D., Jelinek, V. M., et al. (2003). Position statement "stress" and coronary heart disease: Psychosocial risk factors [Electronic version]. Medical Journal of Australia, 178, 272-276.

Cheers, B. (1998). Welfare bushed: Social care in rural Australia. Aldershot: Ashgate.

Coman, G. J., Burrows, G. D., \& Evans, B. J. (2001). Telephone counselling in Australia: Applications and considerations for use. British Journal of Guidance \& Counselling, 29, 247-258.

Community Services Victoria, \& Health Department Victoria. (1988). Review of telephone counselling, information and referral services: Final report. Melbourne: Community Service Victoria.

Fraser, C., Judd, F., Jackson, H., Murray, G., Humphreys, J., \& Hodgins, G. A. (2002). Does one size really fit all? Why the mental health of rural Australia requires further research. Australian Journal of Rural Health, 10, 288-295.

Hambly, G. C., \& Joint Board of Christian Education of Australia and New Zealand. 
(1984). Telephone counselling: a resource for people who want to counsel or care using the telephone. Melbourne: Joint Board of Christian Education of Australia and New Zealand.

Hemmingway, H., \& Marmont, M. (1999). Psychosocial factors in the aetiology and prognosis of coronary heart disease: Systematic review of prospective cohort studies [Electronic version]. British Medical Journal, 318, 1460-1468.

Hetzel, S., Wilkins, V., Carrig, H., Thomas, J., \& Senior, P. (1993). An evaluation of caller satisfaction with solution-focused telephone counselling. Australian Social Work, 46, 51-55.

Hornblow, A. R. (1986). Does telephone counselling have preventive value? Australian and New Zealand Journal of Psychiatry, 20, 23-28.

Hugo, G. (2001). What is really happening in regional and rural populations? In M. F. Rogers \& Y. Collins (Eds.), The future of Australia's country towns (pp.57-71). Bendigo: La Trobe University.

Humphreys, J. S., Mathews-Cowey, S., \& Weinand, H. C. (1997). Factors in accessibility of general practice in rural Australia. Medical Journal of Australia, 166, 577-580.

Kearns, R., \& Moon G. (2002). From medical to health geography: novelty, place and theory after a decade of change. Progress in Human Geography, 26, 5, 605625.

Lazar, A., \& Erera, P. (1998). Telephone helplines as social support. International Social Work, 14, 89-101.

Lester, D. (Ed.). (2002). Crisis intervention and counselling by telephone (2nd ed.). Springfield: Charles C. Thomas.

Letvak, S. (2002). The importance of social support for rural mental health [Electronic version]. Issues in Mental Health Nursing, 23, 259-261.

Lifeline Australia. (2002). Annual report. Retrieved May 4, 2003 from 
http://www.lifeline.org.au/.

Lifeline Australia. (2003). Lifeline Australia Website. Retrieved April 14, 2003, from http://www.lifeline.org.au/

Meadows, G., Singh, B., Burgess, P., \& Bobevski, I. (2002). Psychiatry and the need for mental health care in Australia: Findings from the National Survey of Mental Health and Wellbeing [Electronic version]. Australian and New Zealand Journal of Psychiatry, 36, 210-216

Rosenfield, M. (1997). Counselling by telephone. London: Sage Publications Ltd.

Rosenstock, I. M. (1990). The health beliefs model: Explaining health behaviour through expectancies. In K. Glanz, F. M. Lewis, \& B. F. Rimer (Eds.), Health behaviour and health education: Theory, research, and behaviour and health. San Francisco: Jossey-Bass.

Steel, D., Vella. J., \& Harrington, P. (1996). Quality issues in telephone surveys: Coverage, non-response and quota sampling. Australian Journal of Statistics, 38, 15-34

Young, A., Dobson, A., \& Byles, J. (2001). Access to health services in urban and rural Australia: A level playing field? [Electronic version]. Paper presented at the 6th National Rural Health Conference, Canberra.

Wainer, J., \& Chester, J. (2000). Rural mental health: Neither romanticism nor despair. Australian Journal of Rural Health, 8, 141-147.

Walsh, M. (1995). The health belief model and use of accident and emergency services by the general public. Journal of Advanced Nursing, 22, 694-699.

Watson, R., \& McDonald, J. (2003). Telephone Counselling and Referral Services and Rural Health. Unpublished manuscript available from first author at University of Ballarat, BSSH, P.O Box 663, Ballarat Victoria, 3353, Australia.

Welch, N. (2000). Understanding of the determinants of rural health [Electronic version]. Available Rural and Remote Health Papers 1991-2003 CD-Rom, National Rural Health Allience Inc, 2003. 
Victorian Government Department of Human Services (VGDHS). (2002). Review of counselling services in community health: discussion paper. Melbourne: Victorian Government Department of Human Services. Retrieved on April 12, 2003, from www.dhs.viv.gov.au/phkb 


\title{
Author's Details
}

\author{
Robert Watson, \\ School of Behavioural \& Social Sciences \& Humanities, \\ University of Ballarat \\ University Drive, Mt Helen, \\ Ballarat, \\ PO Box 663, \\ Victoria, 3353, Australia. \\ Phone: (03) 53279197 \\ Email: rwatson@students.ballarat.edu.au. \\ Fax: 0353279840 \\ Dr. John McDonald \\ Director Institute for Regional and Rural Research \\ University of Ballarat \\ PO Box 663 \\ Ballarat, Victoria, Australia, 3353. \\ Telephone (03) 53279745 \\ Fax (03) 53279602 \\ Email j.mcdonald@ballarat.edu.au
}




\section{TABLES}

\section{Table 1}

Summary of questions, response counts, and percentage of total response

\begin{tabular}{|c|c|c|c|}
\hline Question & Response & $n$ & $\%$ \\
\hline \multirow[t]{2}{*}{ Have you heard of the service } & Yes & 91 & 89.2 \\
\hline & No & 11 & 10.8 \\
\hline \multirow[t]{4}{*}{ Knowledge of the Lifeline Service } & Nothing & 3 & 3.3 \\
\hline & Very Little & 51 & 56.0 \\
\hline & Some & 30 & 33.0 \\
\hline & Well Known & 7 & 7.7 \\
\hline \multirow[t]{4}{*}{ Knowledge of operating hours } & Office Hours & 2 & 2.2 \\
\hline & 24hrs/day 7days/week & 64 & 75.8 \\
\hline & Office hours \& weekends & 0 & 0.0 \\
\hline & Don’t Know & 20 & 22.0 \\
\hline \multirow[t]{5}{*}{ Knowledge of contact number } & Number on display/hand & 3 & 2.9 \\
\hline & Phone Book & 79 & 77.5 \\
\hline & Operator & 7 & 6.9 \\
\hline & Other & 4 & 3.9 \\
\hline & Don’t Know & 9 & 8.8 \\
\hline \multirow[t]{2}{*}{ Knowledge of the logo } & Yes & 22 & 24.2 \\
\hline & No & 66 & 75.8 \\
\hline \multirow[t]{5}{*}{ Knowledge of finances } & $100 \%$ Government funded & 31 & 30.4 \\
\hline & Government \& Public & 33 & 32.4 \\
\hline & Donations/community & 23 & 22.5 \\
\hline & Private sector & 0 & 0.0 \\
\hline & Don’t know & 15 & 14.7 \\
\hline \multirow[t]{2}{*}{ Knowledge of sponsor } & Yes & 13 & 14.3 \\
\hline & No & 78 & 85.7 \\
\hline \multirow[t]{4}{*}{ Knowledge of employment conditions } & Paid & 7 & 6.9 \\
\hline & Don’t Know & 8 & 7.8 \\
\hline & Volunteer & 56 & 54.9 \\
\hline & Mixture paid/volunteer & 31 & 30.4 \\
\hline \multirow[t]{4}{*}{ Expected counsellor training } & Specialist training & 44 & 43.1 \\
\hline & Credentialed training & 10 & 9.8 \\
\hline & Professional training & 27 & 26.5 \\
\hline & Other & 21 & 20.6 \\
\hline \multirow[t]{2}{*}{ Expect counsellor to solve problems } & Not expected & 86 & 84.3 \\
\hline & Expected & 16 & 15.7 \\
\hline \multirow[t]{5}{*}{ Value to the community } & Very good & 60 & 58.8 \\
\hline & Good & 28 & 27.5 \\
\hline & Poor & 0 & 0.0 \\
\hline & None & 0 & 0.0 \\
\hline & No idea & 14 & 13.7 \\
\hline Respondent or other used service & Yes & 29 & 28.4 \\
\hline \multirow[t]{2}{*}{ Use another service in preference to LL } & No & 93 & 91.2 \\
\hline & Yes & 9 & 8.8 \\
\hline \multirow[t]{10}{*}{ Circumstance may use service } & Adjustment \& Loss & 18 & 17.6 \\
\hline & Health \& Disability & 17 & 16.7 \\
\hline & Never & 12 & 11.8 \\
\hline & Self \& Society & 12 & 11.8 \\
\hline & Crisis & 11 & 10.8 \\
\hline & Family Challenge & 10 & 9.8 \\
\hline & Abuse \& Violence & 9 & 8.8 \\
\hline & Practical Help & 7 & 6.9 \\
\hline & Life's Direction & 3 & 2.9 \\
\hline & Behaviour Problems & 3 & 2.9 \\
\hline
\end{tabular}

